\title{
Mechanical Properties and Microstructure of the Magnesium Alloy Mg-6.8Y-2.5Zn-0.5Al Produced by Casting and Hot Rolling
}

\author{
Kristina Neh ${ }^{1, a^{*}}$, Madlen Ullmann ${ }^{1, b}$ and Rudolf Kawalla ${ }^{1, c}$ \\ ${ }^{1}$ Technische Universität Bergakademie Freiberg, Institute of Metal Forming, \\ Bernhard-von-Cotta-Straße 4, 09599 Freiberg, Germany \\ akristina.neh@imf.tu-freiberg.de, ${ }^{b}$ madlen.ullmann@imf.tu-freiberg.de, \\ rudolf.kawalla@imf.tu-freiberg.de
}

Keywords: magnesium alloys, LPSO structures, hot rolling

\begin{abstract}
In recent years, magnesium alloys have received much attention as important structural materials for lightweight components in automotive, electronic and space industries because of the low density, high specific strength, high damping capacities and good casting properties. Among various magnesium alloys, rare earth (RE) containing alloys offer high strength, excellent creep resistance and good thermal stability. Long period stacking ordered structures (LPSO) are responsible for the improved property profile in some $\mathrm{Mg}-\mathrm{RE}$ alloys. One promising system is $\mathrm{Mg}-\mathrm{Y}-\mathrm{Zn}$, predominantly processed via extrusion. Only a few studies are focused on hot rolling.

The present paper presents the development of a rolling technology including pass schedule and heat treatment for the magnesium alloy $\mathrm{Mg}-6.8 \mathrm{Y}-2.5 \mathrm{Zn}-0.5 \mathrm{Al}$ in as-cast condition in order to produce sheets with a final thickness of $2.5 \mathrm{~mm}$, which offers a good property profile. The investigations are accompanied by the characterization of the microstructure via optical and scanning electron microscopy as well as the determination of the mechanical properties.
\end{abstract}

\section{Introduction}

AZ31 is the most commonly used magnesium wrought alloy and provides formability, which allows processing via forging, extrusion and rolling. Its average strength properties enable the application as components for medium mechanical stresses. Increasing demands on strength require the usage of magnesium alloys containing higher amounts of aluminum (AZ61, AZ80) or zinc (ZK60). However, their application is limited by a reduced high-temperature strength, which results from the formation of an eutectic structure during solidification, predominantly along the grain boundaries. The $\mathrm{Mg}-\mathrm{Mg}_{17} \mathrm{Al}_{12}$ eutectic softens at low temperatures, which leads to a significant decrease of the strength above $120{ }^{\circ} \mathrm{C}$. This effect is a result of time-dependent softening processes like dislocation climb or grain boundary sliding. In order to improve the high temperature properties of magnesium alloys, solid solution and precipitation hardening for impeding dislocation movement needs to be promoted. Magnesium alloys containing rare earth elements offer a high amount of thermally stable intermetallic phases having a coherent interface with the matrix and therefore preventing the movement of dislocations $[1,2]$.

Other Magnesium alloy systems, especially the Mg-RE-Zn-systems ( RE = Y, Dy, Er, Gd, Ho, $\mathrm{Tm})$, provide excellent high temperature properties and good creep resistance. Their improved property profile is attributed to the presence of LPSO structures [3, 4]. LPSO phases are formed during conventional casting processes. Their basal plane is equal to the (0001) of $\alpha-\mathrm{Mg}$, however, the stacking order is elongated 18 - or 14 -fold $(18 \mathrm{R}$ or $14 \mathrm{H})$ along the c-axis compared to the c-axis length of pure Mg. Magnesium alloys containing LPSO structures are currently subject of research and development and at this stage, are not used in industrial applications.

The presence of LPSO structures in magnesium alloys was already documented by other research groups [3-5]. Fig. 1 shows different magnesium alloys offering pronounced LPSO structures. Kim et al. (2015) have specified thin, plate-like defects with a length varying from $10 \mathrm{~nm}$ to $50 \mathrm{~nm}$ and a volume fraction of $27 \%$ as LPSO structures in a $\mathrm{Mg}_{97} \mathrm{Y}_{2} \mathrm{Zn}_{1}$ (Fig. 1a) alloy [4]. In other magnesium 
alloys, like WZ62 (Fig. 1b) or several Mg-Zn-RE alloys (Fig. 1c), the LPSO structures have a similar occurrence, mostly showing a lamellar or plate-like shape and being located along the grain boundaries of the $\alpha-\mathrm{Mg}$ matrix [3, 5-7].
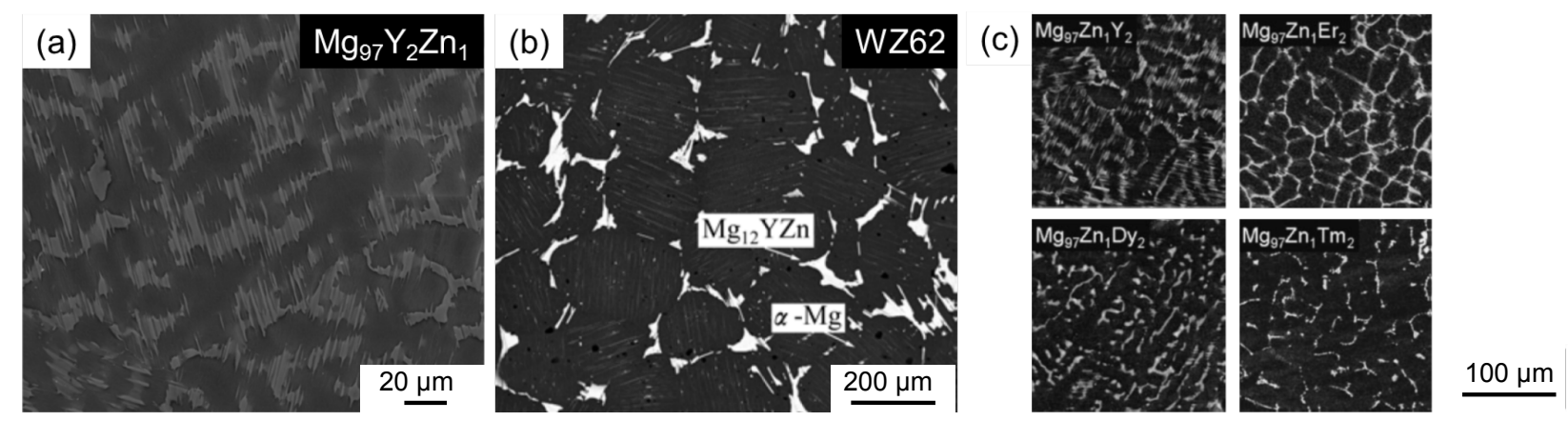

Fig. 1. Scanning electron micrographs (a) $\mathrm{Mg}_{97} \mathrm{Y}_{2} \mathrm{Zn}_{1}$ alloy after solution treatment with grains of the $\alpha-\mathrm{Mg}$ matrix (dark grey) and interdendritic LPSO phases (grey) [4], (b) WZ62 after solution treatment [5] and (c) several Mg-Zn-RE alloys after homogenization [3]

Currently only a few studies are dealing with the hot rolling of magnesium alloys containing yttrium or zinc as main alloying elements [8-10]. In these works the temperature range of hot rolling was restricted to values between $350{ }^{\circ} \mathrm{C}$ and $420{ }^{\circ} \mathrm{C}$. The reduction per pass was varied from $5 \%$ to $25 \%$. Therefore, in this work, a rolling technology including pass schedule and heat treatment was developed for the magnesium alloy $\mathrm{Mg}-6.8 \mathrm{Y}-2.5 \mathrm{Zn}-0.5 \mathrm{Al}$ (wt $\%$ ) in as-cast condition in order to produce sheets with a final thickness of $2.5 \mathrm{~mm}$. The investigations were accompanied by the characterization of the microstructure as well as the determination of the mechanical properties.

\section{Experimental Procedure}

Material Delivery. The material used in this investigation was cast $\mathrm{Mg}-6.8 \mathrm{Y}-2.5 \mathrm{Zn}-0.5 \mathrm{Al}$ produced via gravity die casting at the Leibniz Universität Hannover. First, pure magnesium was melted at $740{ }^{\circ} \mathrm{C}$ under protective gas atmosphere. After one hour pure aluminum and a Mg-29Y (wt\%) master alloy were added to the magnesium melt. Continuous mechanical stirring was implemented to ensure uniform mixing of the melt. The temperature was decreased to $710{ }^{\circ} \mathrm{C}$ and subsequently zinc was added. After pouring the melt into the mold it was exposed to air for cooling. Thus, the cast bolts produced in this way have a diameter of $125 \mathrm{~mm}$ and a length of $300 \mathrm{~mm}$.

Heat Treatment. After casting a heat treatment was conducted in order to adjust a homogenous microstructure and to dissolve undesirable precipitations. This homogenization treatment was intended for providing a raw material with beneficial properties for subsequent hot rolling. The heat treatment was performed in an air circulation furnace under variation of temperature and time, followed by water quenching. Based on former investigations, which focus on heat treatments of zinc and yttrium containing magnesium alloys [11-13], the temperature was set to $400{ }^{\circ} \mathrm{C}, 450{ }^{\circ} \mathrm{C}$ and $500{ }^{\circ} \mathrm{C}$. Holding time was $2 \mathrm{~h}, 6 \mathrm{~h}, 12 \mathrm{~h}$ and $24 \mathrm{~h}$.

Plain strain compression tests. Plain strain compression tests under process-oriented conditions were carried out in the servo-hydraulic hot deformation simulator at the Institute of Metal Forming. Isothermal flow curves were derived from the recorded force-displacement data, considering the correction of the measured values with regard to dissipation energy and friction. Flow curves provide a basis for describing the hardening and softening processes in the material, enabling the determination of energy requirements as well as the estimation of the microstructure. The deformation temperature $\left(300^{\circ} \mathrm{C}, 400{ }^{\circ} \mathrm{C}\right.$ and $\left.500{ }^{\circ} \mathrm{C}\right)$ was adjusted using an air circulating furnace with a low heating rate, and were held at that temperature for 15 minutes to homogenize the temperature over the cross section. This was followed by continuous compression testing using deformation rates ranging from $0.1 \mathrm{~s}^{-1}, 1 \mathrm{~s}^{-1}$ and $10 \mathrm{~s}^{-1}$. Subsequently, the samples were deformed to 
an effective strain of $\varphi_{\mathrm{v}}=0.8$. At least three tests were carried out per forming condition to guarantee a sufficient degree of statistical certainty.

Hot Rolling. For hot rolling discs (diameter of $125 \mathrm{~mm}$ ) with a height of $10 \mathrm{~mm}$ were cut from the bolts. These discs were rolled on a laboratory rolling mill in several passes. Technical data of the used rolling mill are summarized in Table 1. Pass schedule, rolling speed and temperature regime were set based on the results of the plain strain compression tests taking into account the formability as a function of temperature and deformation rate. Results of hot rolling have revealed that a final heat treatment is required.

Table 1 . Technical data of the used rolling mill (laboratory scale)

\begin{tabular}{|ll|l|}
\hline roll diameter & {$[\mathrm{mm}]$} & 360 \\
\hline maximum rolling force & {$[\mathrm{kN}]$} & 2400 \\
\hline maximum rolling torque & {$[\mathrm{kNm}]$} & 60 \\
\hline
\end{tabular}

Microstructural Characterization and Tensile Testing. Samples were taken for the characterization of the microstructural evolution using optical microscopy as well as scanning electron microscopy. EDX (Energy Dispersive X-ray Analysis) and XRD (XRay Diffraction) analysis were conducted to determine chemical composition of structure constituents. Linear intercept method was applied for the measurement of the grain size. Mechanical properties of the rolled sheets were determined by tensile testing at room temperature.

\section{Results and Discussion}

As-cast Condition. The microstructure of the as-cast Mg-6.8Y-2.5Zn-0.5Al alloy (Fig. 2) contains dendrites of the $\alpha-\mathrm{Mg}$ and an intermetallic phase, which is predominantly located in the interdendritic areas. These results are comparable to previously published works, i. a. in $[5,13]$. The chemical composition of the magnesium matrix (Fig. 2b, (1)) was determined being Mg-0.97Y$0.53 \mathrm{Zn}($ at.- $\%)$. The amount of $\mathrm{Y}$ and $\mathrm{Zn}$ in the interdendritic phase (Fig. $2 \mathrm{~b},(2))$ ranges from 4.95 at. $-\% \mathrm{Zn}$ and 6.42 at.- $\% \mathrm{Y}$ to 5.15 at.- $\%$ and 7.25 at.- $\%$, respectively. Consistent with the results of other research groups [13-15] and based on the results of the XRD analysis (Fig. 3), the chemical composition of the intermetallic phases located between the dendrites of the $\alpha$-Mg matrix was established being $\mathrm{Mg}_{12} \mathrm{YZn}$. According to the literature, i. a. in [16], the $\mathrm{Mg}_{12} \mathrm{YZn}$ phase belongs to the LPSO structures. The fraction of the LPSO phase amounts to $20 \%$.
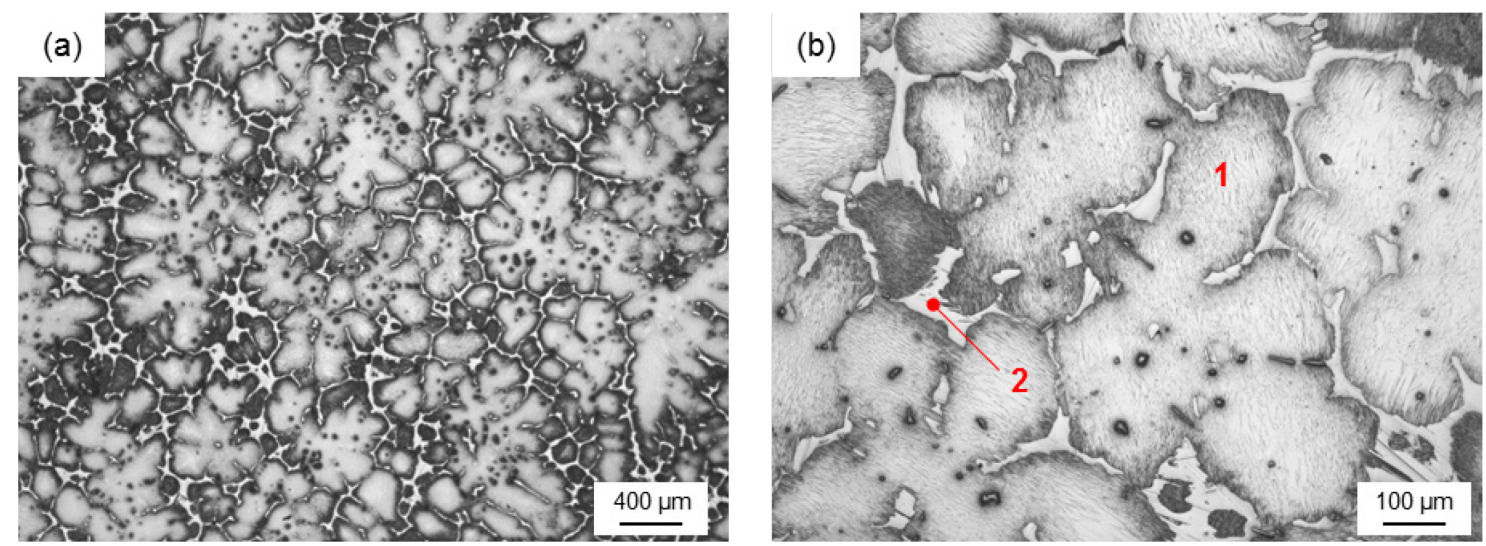

Fig. 2. Microstructure of the Mg-6.8Y-2.5Zn-0.5Al alloy in as-cast condition (a) overview and (b) detail with (1) magnesium matrix and (2) interdendritic phase 


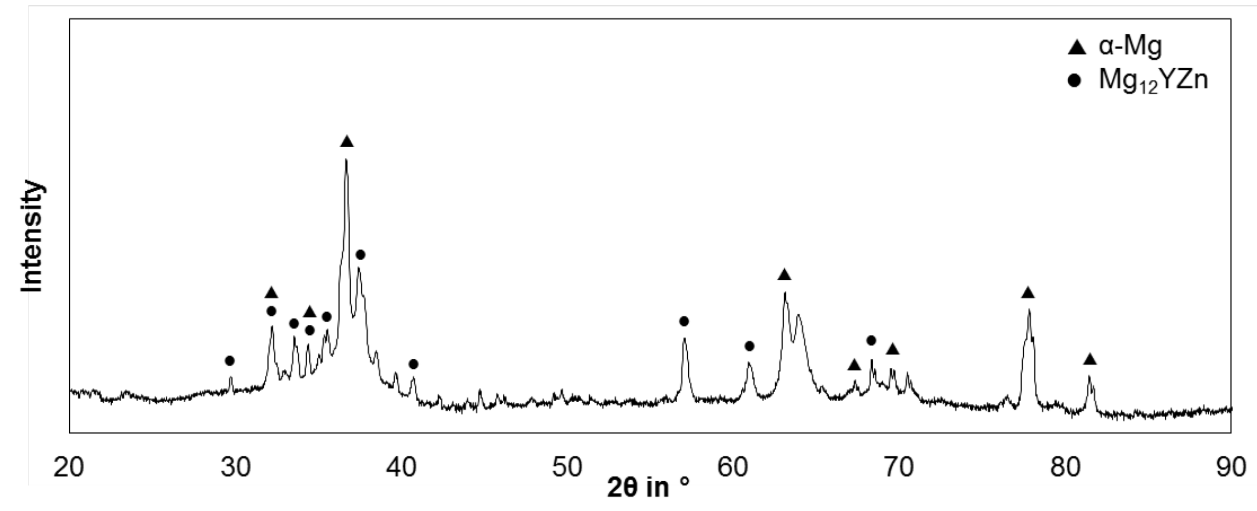

Fig. 3. XRD pattern of the Mg-6.8Y-2.5Zn-0.5Al alloy in as-cast condition

Furthermore, particles and precipitations with different shapes arise occasionally. This includes lamellar structures, probably consisting of two phases with different chemical composition, cuboid shaped particles and needle-like phases (Fig. 4). The first mentioned (Fig. 4a, (3)) seems to be an eutectic phase, which predominantly exhibits magnesium as well as 17 at.- $\% \mathrm{Zn}$ and 10 at.-\% Y. This agrees with previous studies [17] providing an eutectic phase in the Mg-9RY-4Zn alloy with a similar chemical composition. The cuboid particles (Fig. 4b, (4)) appear to be of pure Y being a residue from the casting process. Finally, the small needle-like structures (Fig. 4c, (5)) occur only rarely and contain, besides the main alloying elements, amounts of aluminum varying from 6.5 at. $-\%$ to 47 at. $-\%$.
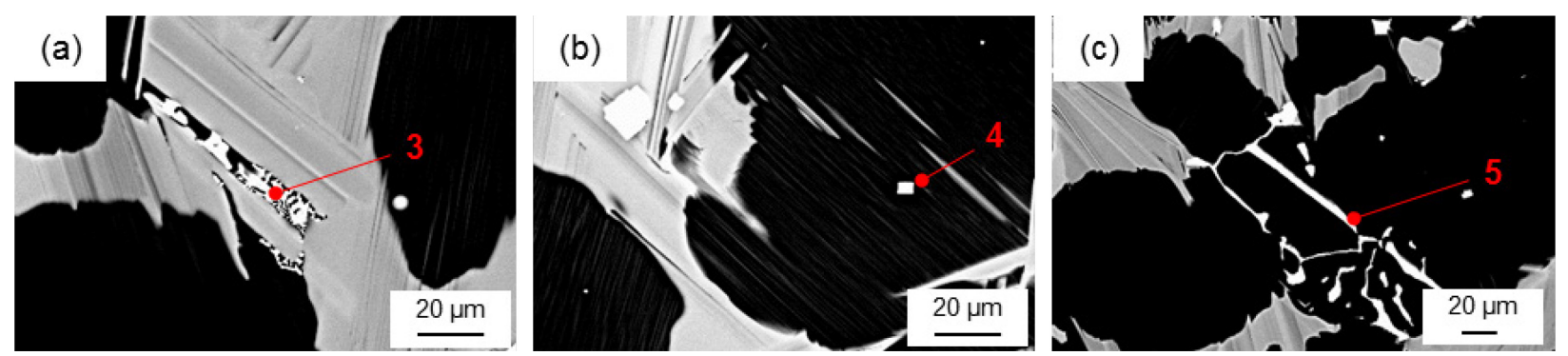

Fig. 4. SEM micrographs of the Mg-6.8Y-2.5Zn-0.5Al alloy in as-cast condition (a) lamellar structure (3) seems to be an eutectic phase, (b) cuboid shaped (4) particles and (c) small, needle-like phases (5) containing various amounts of aluminum

Heat Treatment. In the literature, focused on the processing of Mg-Y-Zn alloys, the effect of the homogenization is only rarely considered. In this work different temperature-time-regimes were tested in order to adjust a homogeneous microstructure. However, microstructural characterization has shown, that neither high temperatures $\left(500^{\circ} \mathrm{C}\right)$ nor long holding times $(24 \mathrm{~h})$ lead to changes in the microstructure.

Hardening and Softening Behavior. The plain strain compression tests were performed at different temperatures and strain rates. Fig. 5 summarizes the flow curves of the Mg-6.8Y-2.5Zn$0.5 \mathrm{Al}$. Flow curves at increased temperatures and low strain rates show a similar progression. Initially, the curve ascends due to the hardening of the material until reaching the maximum of the flow stress. The beginning of softening processes leads to decreasing flow stresses and finally reaches the steady state. Increasing temperatures result in lower flow stresses. Generally, the flow stress increases with higher strain rates (Fig. 5). A strain rate of $10 \mathrm{~s}^{-1}$ results in a considerable hardening of the material due to the quick forming and consequently insufficient time for softening processes. At a forming temperature up to $400{ }^{\circ} \mathrm{C}$ only recovery occurs. As can be seen from Fig. 5a, the flow stress remains at $125 \mathrm{MPa}$. The flow curve at a forming temperature of $500{ }^{\circ} \mathrm{C}$ suggests that recrystallization occurs and leads to the softening of the material. For a more accurate analysis microstructural characterization of the specimen was performed. The local plastic strain in the areas chosen for this examination corresponds to the equivalent plastic strain. Fig. 6a shows an optical micrograph of this area referring to the specimen tested at $500{ }^{\circ} \mathrm{C}$. 

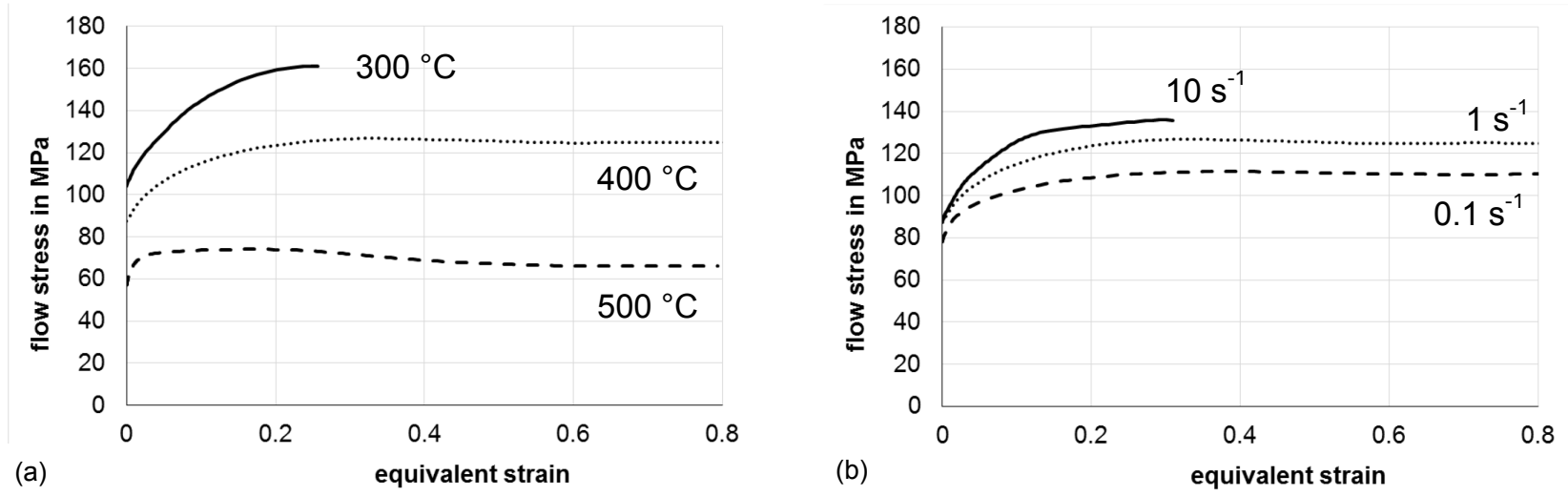

Fig. 5. Flow curves of the Mg-6.8Y-2.5Zn-0.5Al alloy: (a) at different testing temperatures and a strain rate of $1 \mathrm{~s}^{-1}$ and (b) at different strain rates and a temperature of $400{ }^{\circ} \mathrm{C}$

It is obvious that a high amount of recrystallized, very fine grains develop at the interface of the magnesium matrix and the $\mathrm{Mg}_{12} \mathrm{YZn}$ phase. This effect is not noticeable at lower forming temperatures $\left(300^{\circ} \mathrm{C}\right.$ and $\left.400{ }^{\circ} \mathrm{C}\right)$. Additionally, the microstructural analysis provides insight into the predominant deformation mechanisms, which ordinarily arise in magnesium alloys containing LPSO structures. Fig. 6b shows the characteristic kink bands, which are a result of kinking. The development of kink bands is contingent on the formation and simultaneous sliding of dislocations having opposite signs on the basal planes [4, 18].
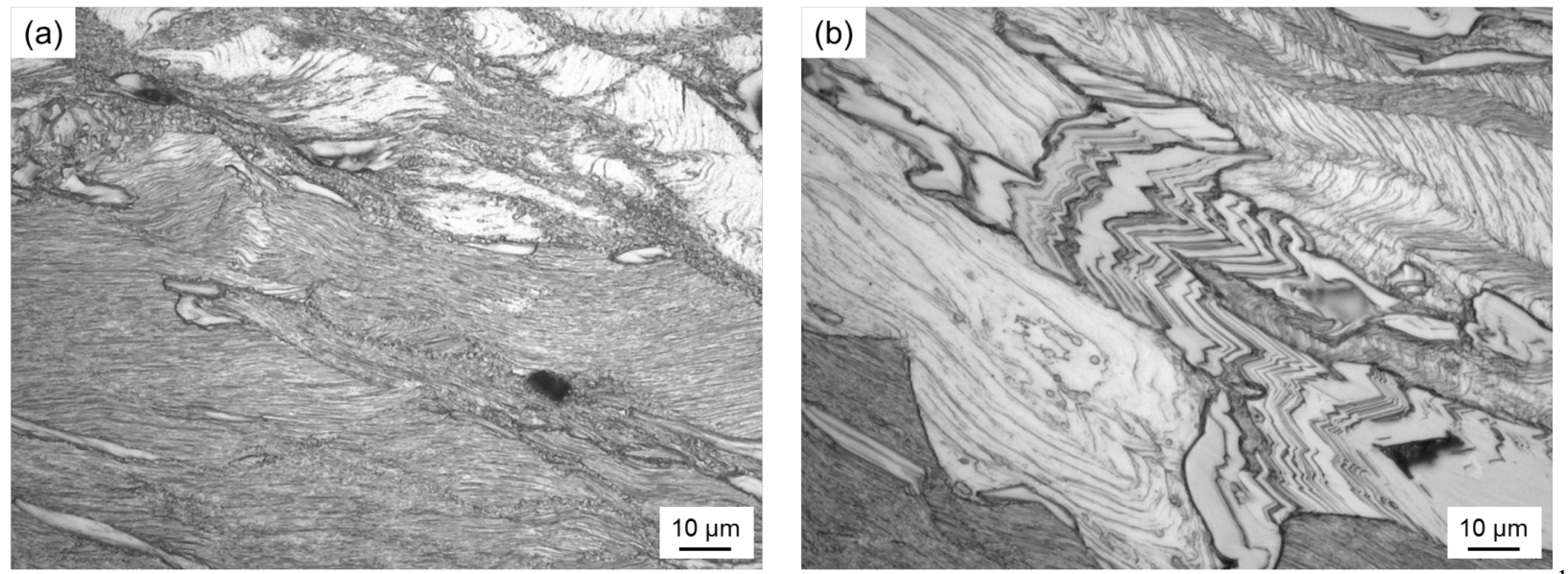

Fig. 6. Optical micrographs of the specimen after plan strain compression test at $500{ }^{\circ} \mathrm{C}$ and $1 \mathrm{~s}^{-1}$ : (a) detail and (b) kink bands

Hot Rolling and Final Properties. Hot rolling was conducted using a reversing mill in laboratory scale. The rolls were heated up to $120^{\circ} \mathrm{C}$ prior to rolling in order to minimize loss of temperature. Rolling speed was $1 \mathrm{~m} / \mathrm{s}$. The relatively high rolling speeds result from the reduction of heat loss during the rolling process, preventing the formation of cracks. The discs were heated up in an air circulating furnace to a rolling temperature of $500{ }^{\circ} \mathrm{C}$ for $2 \mathrm{~h}$ in order to ensure an homogeneous temperature distribution throughout the sample volume. In preliminary tests, different temperatures and reductions per pass were investigated in order to find suitable processing parameters for the hot rolling of the $\mathrm{Mg}-6.8 \mathrm{Y}-2.5 \mathrm{Zn}-0.5 \mathrm{Al}$ alloy. Fig. 7 provides an overview of the tested parameters assessing their suitability. Consequently, high forming temperatures are required in order to prevent the formation of cracks. A reduction per pass of $20 \%$ still provides good results. In the present work a pass schedule consisting of 5 passes with a reduction of $20 \%$ was chosen. In order to adjust the sheet thickness of $2.5 \mathrm{~mm}$ a final pass with a reduction of $30 \%$ was performed. After each pass an intermediate heat treatment was required in order to realize recrystallization. This heat treatment was carried out at $450{ }^{\circ} \mathrm{C}, 500{ }^{\circ} \mathrm{C}$ and $550{ }^{\circ} \mathrm{C}$ for a holding time of $2 \mathrm{~h}$. Microstructural characterization was implemented to specimens with a thickness of $5.5 \mathrm{~mm}$ (intermediate state) and $2.5 \mathrm{~mm}$ (final sheet). 


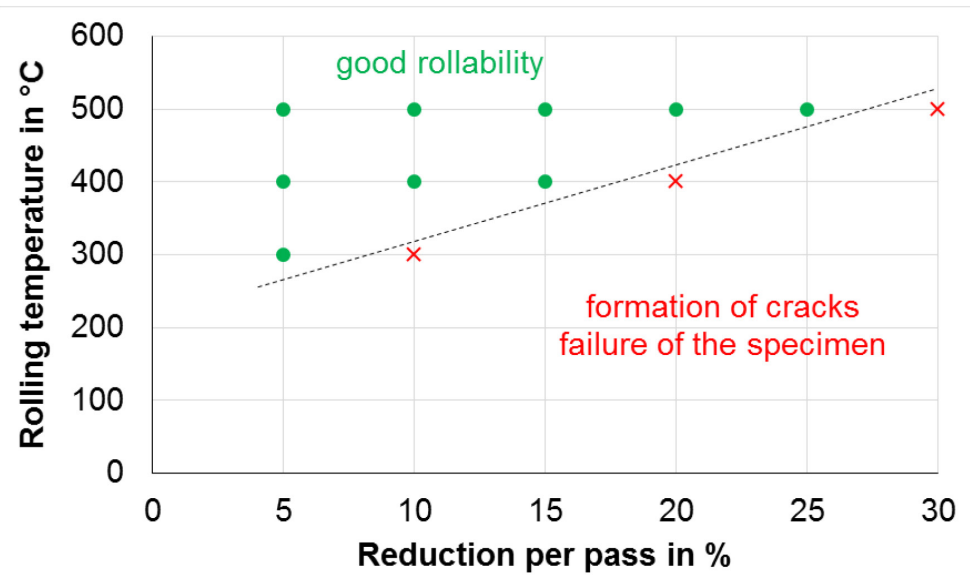

Fig. 7. Overview of rollability depending on processing parameters (temperature and reduction per pass) for the hot rolling of the Mg-6.8Y $-2.5 \mathrm{Zn}-0.5 \mathrm{Al}$ based on the results of preliminary rolling tests

The intermediate state of the hot rolled Mg-6.8Y-2.5Zn-0.5Al alloy in different conditions is shown in Fig. 8. The $\alpha-\mathrm{Mg}$ grains and the $\mathrm{Mg}_{12} \mathrm{YZn}$ phase are elongated in rolling direction. Due to the intermediate heat treatment, recrystallization occurs. Even at the lowest temperature, tested for intermediate heat treatment $\left(450^{\circ} \mathrm{C}\right)$, recrystallization was induced and grains with an average cord length of $5 \mu \mathrm{m}$ originate in the vicinity of the LPSO phase. The interface between the LPSO phase and the magnesium matrix can act as nucleation site for recrystallization because of a high dislocation density and fine sub-grains. This effect is known as particle stimulated nucleation (PSN) [19]. As mentioned before, in magnesium alloys containing LPSO phases kinking is the predominant deformation mechanism. The development of kink bands requires the presence of dislocations. Considering the results of the plain strain compression tests, it seems that the demands for the occurrence of PSN are fulfilled. Increasing the temperature of the intermediate heat treatment results in growth of the recrystallized grains, whereas the LPSO phase diminishes. At $550^{\circ}$ an undesirable degree of grain growth is reached. Furthermore, the melting of grain boundaries may occur. Hence, intermediate heat treatment was carried out at a temperature of $500{ }^{\circ} \mathrm{C}$ and a holding time of $2 \mathrm{~h}$.

The micrograph of the detailed microstructure in Fig. 8e offers the development of a needle-like phase within the grains of the magnesium matrix. SEM and EDX analysis (Fig. 9) reveal that during the intermediate heat treatment the enriched areas of $\mathrm{Y}$ and $\mathrm{Zn}$ diminish, while recrystallization takes place, and a needle-like $\mathrm{Mg}_{12} \mathrm{YZn}$ phase is formed.

The plates with a thickness of $5.5 \mathrm{~mm}$ are rolled in two passes with a reduction of $20 \%$ and a final rolling pass with a reduction of $30 \%$. Intermediate heat treatment was performed at $500{ }^{\circ} \mathrm{C}$ and $2 \mathrm{~h}$. The microstructure of the hot rolled Mg-6.8Y-2.5Zn-0.5Al alloy with a final thickness of $2.5 \mathrm{~mm}$ is depicted in Fig. 10. In order to adjust a homogeneous microstructure a final heat treatment at $450{ }^{\circ} \mathrm{C}$ and $2 \mathrm{~h}$ holding time was carried out. As can be seen, providing sufficient parameters for the final heat treatment requires more investigations in a broader field of temperatures and holding times. Additionally, undesirable grain growth must be prevented. During the final heat treatment recrystallization occurs and leads to the development of grains at the interface between the LPSO phase and the magnesium matrix. The occurring processes are similar to the above mentioned. Unfortunately, the present conditions were not able to ensure a complete recrystallized microstructure.

The micrograph of the detailed microstructure in Fig. 8e offers the development of a needle-like phase within the grains of the magnesium matrix. SEM and EDX analysis (Fig. 9) reveal that during the intermediate heat treatment the enriched areas of $\mathrm{Y}$ and $\mathrm{Zn}$ diminish, while recrystallization takes place, and a needle-like $\mathrm{Mg}_{12} \mathrm{YZn}$ phase is formed. 

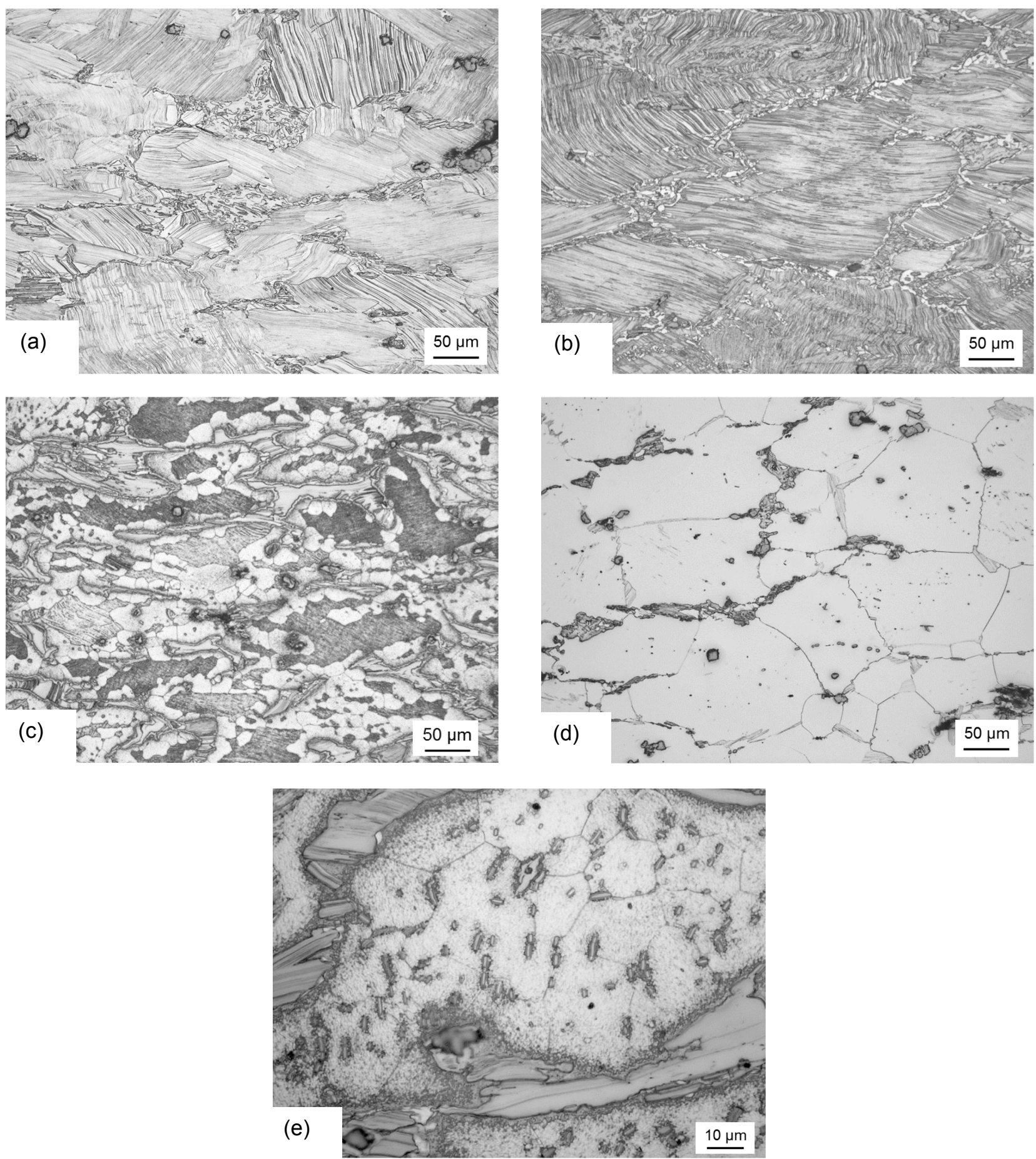

Fig. 8. Mg-6.8Y-2.5Zn-0.5Al alloy after hot rolling (intermediate state, thickness $5.5 \mathrm{~mm}$ ) in (a) asrolled condition and after intermediate heat treatment at (b) $450{ }^{\circ} \mathrm{C}$, (c) $500{ }^{\circ} \mathrm{C}$ and (d) $550{ }^{\circ} \mathrm{C}$ with a holding time of $2 \mathrm{~h}$ and (e) detailed micrograph after intermediate heat treatment at $500{ }^{\circ} \mathrm{C}, 2 \mathrm{~h}$ (rolling direction $\rightarrow$ )

The plates with a thickness of $5.5 \mathrm{~mm}$ are rolled in two passes with a reduction of $20 \%$ and a final rolling pass with a reduction of $30 \%$. Intermediate heat treatment was performed at $500{ }^{\circ} \mathrm{C}$ and $2 \mathrm{~h}$. The microstructure of the hot rolled Mg-6.8Y-2.5Zn-0.5Al alloy with a final thickness of $2.5 \mathrm{~mm}$ is shown in Fig. 10. Like illustrated, more investigations in a broader field of temperatures and holding times are required for the intermediate heat treatment. Additionally, undesirable grain growth must be prevented. During the final heat treatment recrystallization occurs and leads to the development of grains at the interface between the LPSO phase and the magnesium matrix. The occurring processes are similar to the above mentioned. Unfortunately, the present conditions were 
not able to adjust a complete recrystallized microstructure. However, high temperatures would be able to promote recrystallization, but deterioration of mechanical properties is expected.
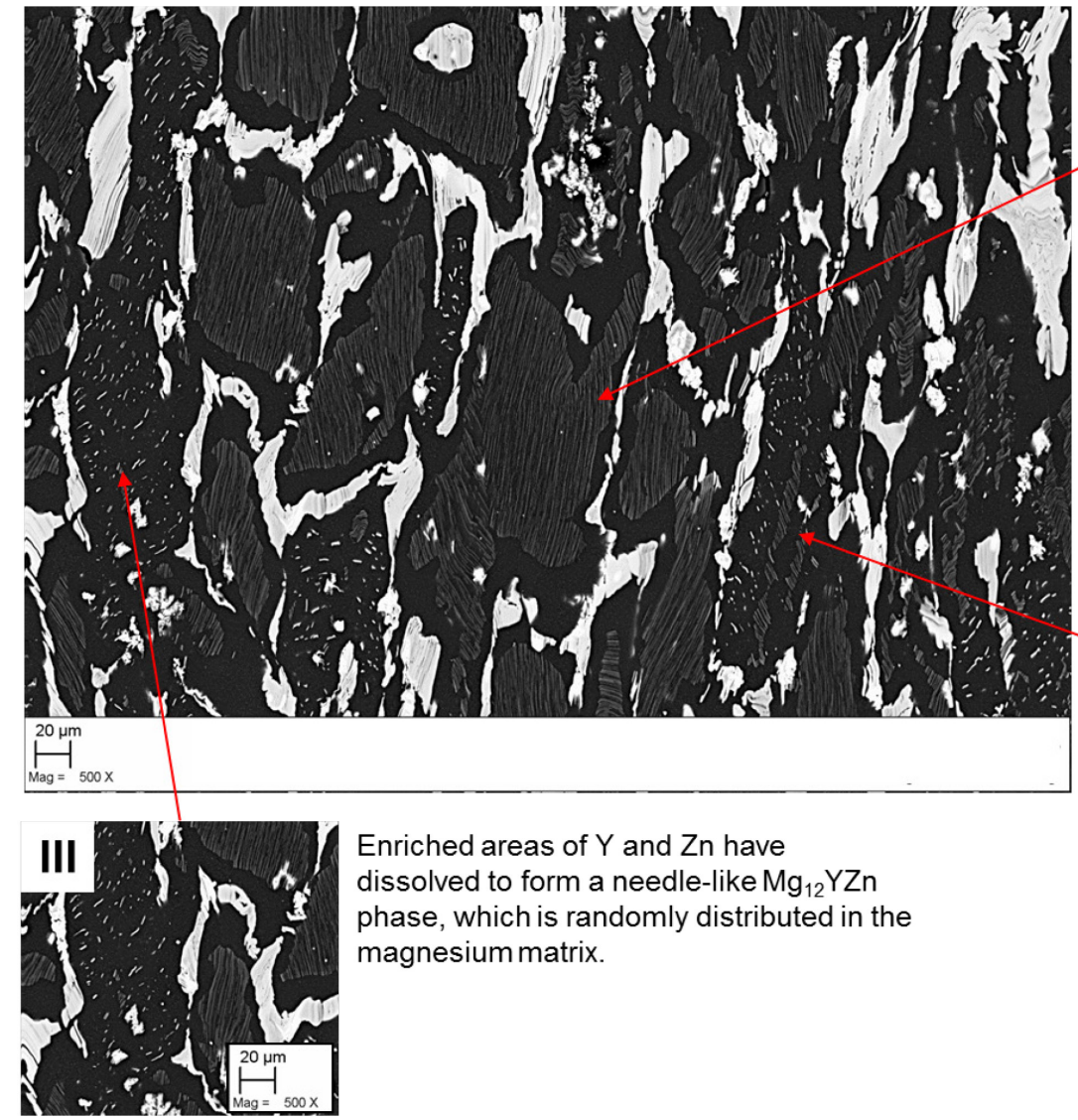

Enriched areas of $Y$ and $Z n$ have

dissolved to form a needle-like $\mathrm{Mg}_{12} \mathrm{YZn}$ phase, which is randomly distributed in the magnesium matrix.

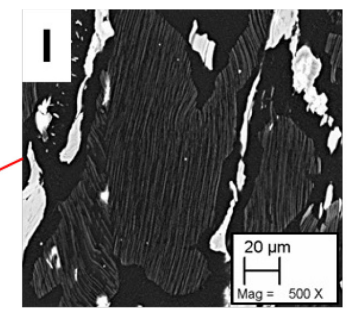

Lamellar structures seems to be enriched areas ( $\mathrm{Y}$ and $\mathrm{Zn})$ in the magnesium matrix.

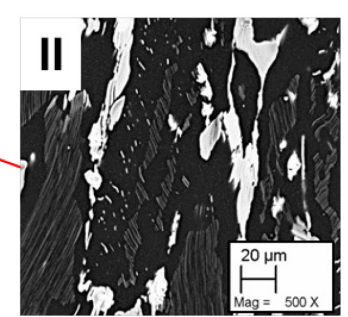

Lamellar structures disappear. Beginning recrystallization leads to the development of new grains along the LPSO phase.

Fig. 9. SEM and EDX analysis of the hot rolled Mg-6.8Y-2.5Zn-0.5Al alloy after the intermediate heat treatment $\left(500^{\circ} \mathrm{C}, 2 \mathrm{~h}\right)$

The mechanical properties of the Mg-6.8Y-2.5Zn-0.5Al alloy are shown in Fig. 11. After casting the tested magnesium alloy exhibits moderate strengths and, typical for cast magnesium, a low elongation at fracture. After hot rolling and final annealing, good mechanical properties were attained: yield strength is $295 \mathrm{MPa}$ and ultimate tensile strength is $345 \mathrm{MPa}$. Elongation at fracture is improved slightly compared to the cast condition, but remains at a relatively low level, especially in comparison to magnesium alloys of the AZ-system or Mg-Zn-Y alloys with a high amount of $\mathrm{Zn}$ (Fig. 11b). Regarding yield strength, the investigated Mg-Y-Zn alloy provides higher values than WE54 and other Mg-Y-Zn alloys. Only Mg-Y-Ni alloys offer a higher yield strength.

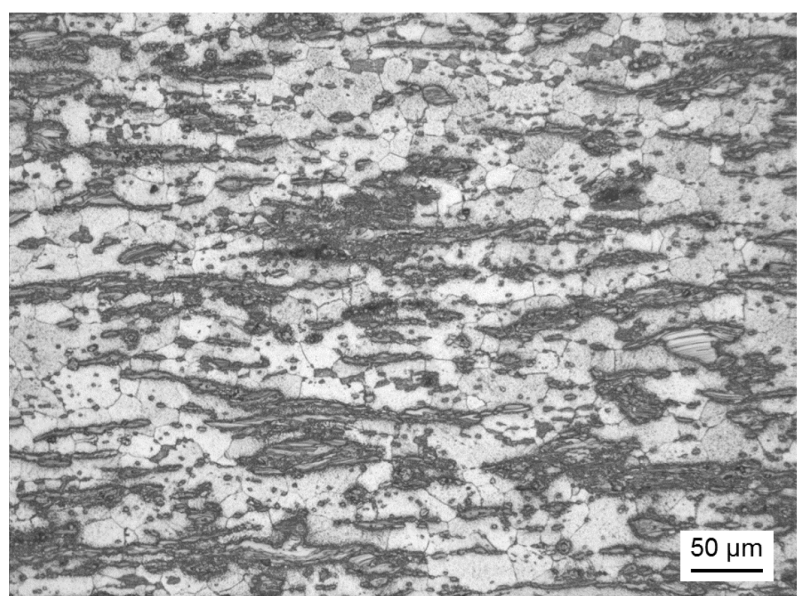

Fig. 10. Optical micrograph of the Mg-6.8Y $-2.5 \mathrm{Zn}-0.5 \mathrm{Al}$ alloy after hot rolling with a final thickness of $2.5 \mathrm{~mm}$ and a final heat treatment $\left(450{ }^{\circ} \mathrm{C}, 2 \mathrm{~h}\right)$ 


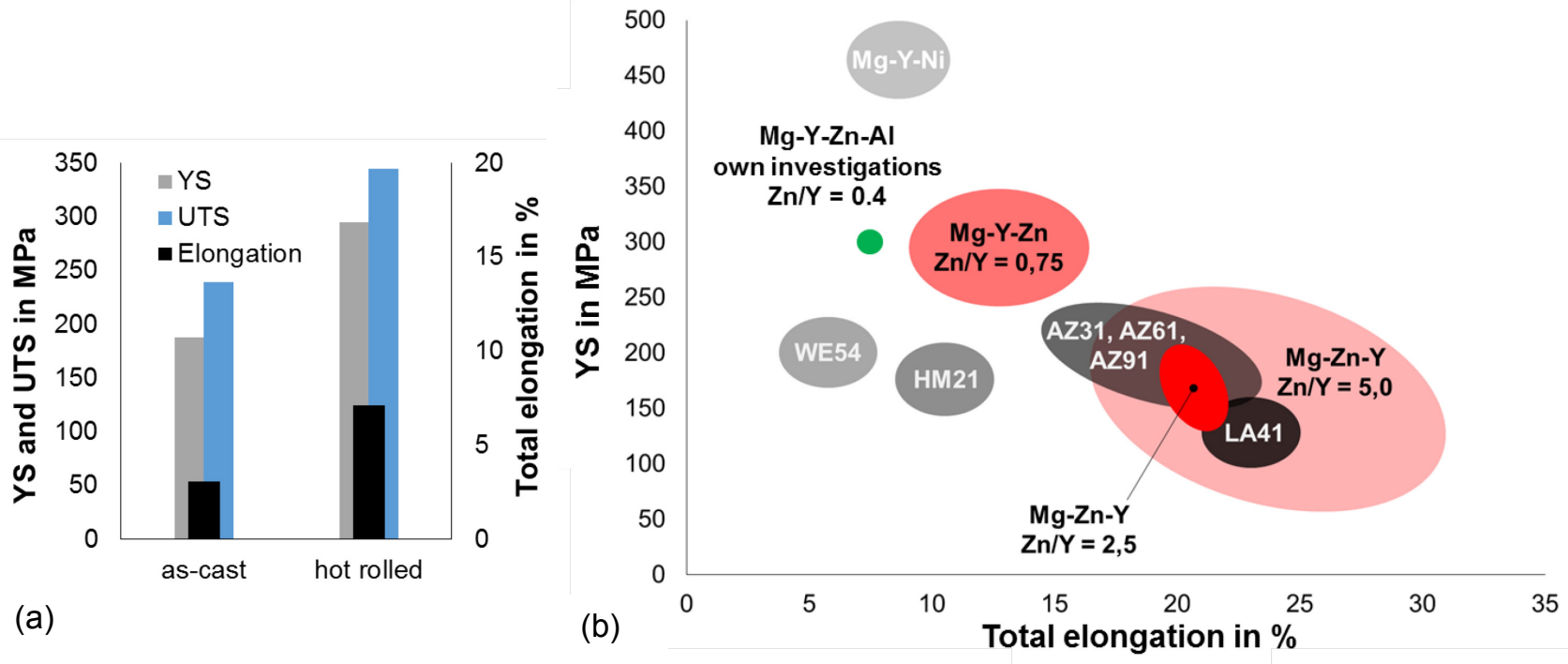

Fig. 11. Mechanical properties of the Mg-6.8Y-2.5Zn-0.5Al alloy (a) in as-cast and hot rolled condition (after final heat treatment) and (b) in comparison to other magnesium alloys (produced via hot rolling) [8-10, 20,21]

\section{Summary}

The present paper summarizes casting and hot rolling of the magnesium alloy Mg-6.8Y-2.5Zn$0.5 \mathrm{Al}$ alloy. Substantial results are presented below:

- The microstructure of the Mg-6.8Y-2.5Zn-0.5Al alloy in as-cast condition contains dendrites of the $\alpha-\mathrm{Mg}$ and an intermetallic phase, which was established being $\mathrm{Mg}_{12} \mathrm{YZn}$.. Furthermore, particles and precipitations with different shapes and chemical compositions arise occasionally.

- For heat treatment after casting, different temperature-time-regimes were tested. However, neither high temperatures $\left(500{ }^{\circ} \mathrm{C}\right)$ nor long holding times $(24 \mathrm{~h})$ lead to changes in the microstructure. However, a minor degree of deformation induces recrystallization during a following heat treatment.

- Hot rolling was performed with a 6-pass-schedule with reductions per pass of $20 \%$ and $30 \%$ (final pass) at $500{ }^{\circ} \mathrm{C}$. The final sheets with a thickness of $2.5 \mathrm{~mm}$ offer good mechanical properties with strength values higher than WE54 and a moderate elongation at fracture.

\section{References}

[1] C. Kammer, Magnesium Taschenbuch, Aluminium-Verlag Düsseldorf, 2000.

[2] C. Bettles, M. Barnett, Advances in wrought magnesium alloys, Woodhead Publishing Limited Oxford, 2012.

[3] Y. Kawamura, M. Yamasaki, Formation and mechanical properties of Mg97Zn1RE2 alloys with long-period stacking ordered structure, Mater. Trans. 48 (11) (2007) 2986-2992.

[4] J. K. Kim, S. Sandlöbes, D. Raabe, On the room temperature deformation mechanisms of a Mg-Y-Zn alloy with long-period-stacking-ordered structures, Acta Mater. 82 (2015) 414-423.

[5] B. Q. Shi, R. S. Chen, W. Ke, Structure processing route on texture and mechanical properties of WZ62 alloy, Trans. Nonferrous Met. Soc. China 21 (2011) 830-835.

[6] M. Yamasaki, K. Hashimoto, et al., Effect of multimodal microstructure evolution on mechanical properties of Mg-Zn-Y extruded alloy, Acta Mater. 59 (2011) 3646-3658. 
[7] B. Wang, S. Xiong, Y. Liu, Tensile fracture of as-cast and hot rolled Mg-Zn-Y alloy with longperiod stacking phase, Trans. of Nonferrous Met. Soc. China 20 (2010) s488-s492.

[8] D. H. Bae, M. H. Lee, et al., Application of quasicrystalline particles as a strengthening phase in Mg-Zn-Y alloys, J. Alloys Compd. 342 (2002) 445-450.

[9] T. Itoi, T. Inazawa, et al., Microstructure and mechanical properties of $\mathrm{Mg}-\mathrm{Zn}-\mathrm{Y}$ alloy sheet prepared by hot-rolling, Mater. Sci. Eng. A, 560 (2013) 216-223.

[10] J. Y. Lee, D. H. Kim., et al., Effects of Zn/Y ratio on microstructure and mechanical properties of Mg-Zn-Y alloys, Mater. Lett. 59 (2005) 3801-3805.

[11]H. Watanabe, M. Mukai, et al., Mechanical properties of Mg-Y-Zn alloy processed by equalchannel-angular extrusion, Mater. Trans. 44 (4) (2003) 463-467.

[12] Y. M. Zhu, A. J. Morton, et al., Improvement in the age-hardening response of Mg-Y-Zn alloys by Ag additions, Scr. Mater. 58 (2008) 525-528.

[13]B. Chen, D. Lin, et al., Effects of yttrium and zinc addition on the microstructure and mechanical properties of Mg-Y-Zn alloys, J. Mater. Sci. 45 (2010) 2510-2517.

[14]H. Watanabe, Fine-grain processing by equal channel angular extrusion of rapidly quenched bulk Mg-Y-Zn alloy, J. Mater. Res. 20 (1) (2005) 93-101.

[15]B. Wang, Y. Liu, et al., Morphological evolutions of cast and melt-spun Mg97Zn1Y2 alloys during deformation and heat-treating, Trans. Nonferrous Met. Soc. China 18 (2008) s69-s75.

[16] J. Geng, X. Teng, et al., Microstructure transformations in the heat-treated Mg-Zn-Y alloy, J. Alloys Compd. 577 (2013) 498-506.

[17]Z. Leng, J. Zhang, et al., Microstructure and high mechanical properties of Mg-9RY-4Zn (RY: Y-rich misch metal) alloy with long period stacking ordered phase, Mater. Sci. Eng. A, 540 (2012) $38-45$.

[18]X. H. Shao, Z. Q. Yang, et al., Strengthening and toughening mechanisms in Mg-Zn-Y alloy with long period stacking ordered structure, Acta Mater. 58 (2010) 4760-4771.

[19]L. Ko, Particle Stimulated Nucleation: Deformation around Particles, [Thesis]. Manchester, UK: The University of Manchester, 2014.

[20] T. Itoi, K. Takahashi, et al., A high-strength Mg-Ni-Y alloy sheet with a long-period ordered phase prepared by hot rolling, Scr. Mater. 59 (2008) 1155-1158.

[21]D. H. Bae, S. H. Kim, et al., Deformation behavior of Mg-Zn-Y alloys reinforced by icosahedral quasicrystalline particles, Acta Mater. 50 (2002) 2343-2356. 